\title{
Pelatihan TPACK (Technological, Pedagogical, Content Knowledge) Bagi Guru Bahasa Inggris di Kabupaten Karawang Jawa Barat
}

\author{
Muhammad Reza Pahlevi ${ }^{1)}$, Iwan Ridwan ${ }^{2}$, Acep Bahrum Kamil ${ }^{3)}$ \\ ${ }^{122) 3)}$ Universitas Singaperbangsa Karawang, Karawang, Indonesia \\ Corresponding Author: Muhammad Reza Pahlevi, mreza.pahlevi@fkip.unsika.ac.id
}

\begin{abstract}
Abstrak: Isu penggunaan teknologi dalam bidang pendidikan khususnya pengajaran tidak dapat dihindari apalagi dalam masa Pandemi Covid-19 dimana pembelajaran dilaksanakan secara daring. Bagaimanapun pembelajaran daring masih dipahami dan dilaksanakan dengan menekankan penggunaan platform tanpa diintegrasikan sisi pedagogi dan materi ajarnya. Sehingga kegiatan pembelajaran daring belum melibatkan siswa secara aktif dalam pembelajaran daring yang berisi teknologi, pedagogi serta materi ajar (TPACK). Oleh karena itu, pengabdian kepada masyarakat ini bertujuan untuk membantu guru-guru bahasa Inggris dalam mengintegrasikan penggunaan teknologi, pedagogi serta materi ajarnya. Partisapan pengabdian ini adalah guru bahasa Inggris di Karawang. Pelaksaaan pelatihan ini dilakukan dengan memberikan pelatihan terkait integrasi TPACK yang terdiri dari 3 materi yaitu integrasi TPACK dalam lesson plan, TELL in language learning \& teaching, dan reflective practice and exploratory practice within Tesol teachers. Setelah mengikuti pelatihan para guru bahasa Inggris dapat membuat RPP dengan integrasi TPACK, mampu mempraktikan TPACK dalam pembelajaran serta melakukan refleksi setelah pembelajaran. Dapat disimpulkan bahwa pelatihan TPACK membantu guru mengintegrasikan baik penggunaan teknologi, pengajaran serta materi ajar dalam pembelajaran.
\end{abstract}

Kata Kunci: TPACK, Lesson Plan, Reflective Practice

\begin{abstract}
The issue of using technology in education, especially teaching, cannot be avoided. Especially during the Covid-19 Pandemic where learning was carried out online. However, online learning is still understood and implemented by emphasizing the use of platforms without being integrated with the pedagogy and teaching materials. So that online learning activities do not involve students actively in online learning which contains technology, pedagogy and teaching materials (TPACK). Therefore, this community service aims to assist English teachers in integrating the use of technology, pedagogy and teaching materials. This training is carried out by providing training related to TPACK integration which consists of 3 materials, namely TPACK integration in lesson plans, TELL in language learning \& teaching, and reflective practice and exploratory practice within Tesol teachers. After participating in the training, English teachers can make lesson plans with TPACK integration, be able to practice TPACK in learning and reflect after learning. It can be summed up that TPACK training assisted teachers in integrating technology, pedagogy, and content knowledge in learning.
\end{abstract}

Keywords: TPACK, Lesson Plan, Reflective Practice

\section{Pendahuluan}

Pandemi Covid-19 merubah tatanan kehidupan mulai dari sektor kesehatan, ekonomi, dan pendidikan. Dalam sektor pendidikan, pembelajaran diarahkan daring (Kemendikbud, 2020). Hal ini menjadi tantangan tersendiri bagi guru karena belum terbiasa belajar via daring. Disisi

Submitted: 13.12.2020, Revised: 10.03.2021, Accepted: 06.04.2021 
lain pembelajaran harus tetap berjalan dengan melibatkan siswa secara aktif. Bagaimanapun, guru bahasa Inggris telah mengikuti berbagai workshop dan seminar mengenai pemanfaat teknologi dalam pembelajaran bahasa Inggris, namun bagaimana mengintegrasikan teknologi dalam proses pembelajaran belum dikaji lebih mendalam (Drajati, 2020).

Mengintegrasikan baik teknologi, pedagogi maupun materi ajar merupakan hal penting untuk diaplikasikan. Hal ini erat kitannya dengan kerangka Technological, Pedagogical, Content, Knowledge TPACK (Koehler, Mishra, \& Cain, 2013). Integrasi TPACK membantu dalam pelaksanaan pembelajaran daring (Kohler et. al, 2013). Menurut Pinkley (2010) menambahkan dalam kehidupan global dimana teknologi telah menjadi bagian yang integral dalam kehidupan sehari-hari, semakin banyak manusia menggunakan teknologi baik untuk kebutuhan pribadi maupun kebutuhan dalam dunia profesi. Bagaimanapun, guru-guru dalam melaksanakan pembelajaran daring cenderung melaksanakan pembelajaran daring melalui aplikasi. Guru-guru belum megintegrasikan sisi pedagogi dan materi ajar. Hal ini disampaikan oleh Drajati (2020) bahwa guru belum mengintegrasikan TPACK dalam pemebelajaran daring. Sehingga peserta didik belum terlibat secara aktif dalam pembelajaran dan cenderung peserta didik merasa bosan dan terkesan mengabaikan materi ajar yang diberikan oleh guru. Guru-guru bahasa Inggris menghadapi permasalahan terkait integrasi penggunaan teknologi, pedagogi dalam pembelajaran. Sehingga cenderung RPP belum diintegrasikan dengan hal tersebut. Potensi Guru-Guru bahasa Inggris dalam berkontribusi integrasi TPACK sangat strategis mengingat pemerataan pembelajaran diperlukan penggunaan teknologi. Maka perlu untuk melakukan pelatihan integrasi TPACK bagi guru-guru.

Integrasi Pedagogi dan materi ajar menjadi desain pembelajaran daring (Rakerda, 2020). Adapun desain pembelajaran dimulai dari persiapan mengajar (pre-lesson), inti pembelajaran (while-lesson), dan akhir pembelajaran (post lesson) (Drajati, 2020). Ada beberapa penelitian sebelumnya yang mengkaji TPACK dalam pembelajaran. Chai \& Koh (2017) menginvestigasi perubahan beliefs TPACK dan desain melalui the Scaffolded TPACK Lesson Design (STLDM). Hasil penelitiannya mengilustraikan bahwa terdapat signifikan perubahan beliefs dalam penggunaan kerangka TPACK dan pembelajaran melalui STLDM.

Kemudian Cheng (2017) melakukan penelitian tentang persepsi pengajar asli Taiwan terhadap TPACK. Penelitiannya menggunakan survey yang melibatkan 172 guru bahasa Inggris Hakka. Kerangka surveynya meliputi tujuh kriteria yaitu content knowledge (CK), pedagogical knowledge (PK). Technological knowledge (TK), pedagogical content knowledge (PCK), technological pedagogical knowldege (TPK), technological content knowledge (TCK), dan TPACK. Hasil penelitian menunjukkan bahwa meskipun guru yang bahasa ibunya Taiwan secara rata-rata mempersepsikan baik TPACK namun mereka memiliki sedikit kepercayaan diri dalam CK, TK, dan TPK. Sedangkan guru laki-laki yang lebih senior lebih cenderung percaya diri dalam CK, dan guru perempuan senior lebih sedikit kurang percaya diri dalam TK.

Menurut Murphy, DePasquale, dan McNamara (2003) menambahkan banyak sekolah telah berusaha keras untuk menggabungkan teknologi dalam kurikulumnya dengan maksud agar membiasakan para guru dan siswanya dengan teknologi sebagai alat untuk pembelajaran. Pentingnya keterlibatan siswa secara aktif dalam pembelajaran daring, dibutuhkan solusi tepat agar materi yang disampaikan benar-benar dapat dipahami atau dimengerti siswa-siswi dalam proses KBM yang tidak dibatasi oleh ruang dan waktu serta mereka terlibat secara aktif, maka model TPACK merupakan salah satu solusi atau pemecahan masalah yang dapat digunakan para guru dalam proses KBM. Sehingga para guru dapat mengintegrasikan sisi teknologi, pedagogi, dan materi ajar secara bersamaan.

Implementasi TPACK dapat disajikan dengan TELL in language learning \& teaching, Reflective practice, dan exploratory practice within Tesol teacher. Pelatihan TELL in language 
learning difokuskan mengenal media dan platform teknologi dalam pembelajaran. Hal ini membantu guru dalam melaksanakan pembelajaran melalui pemanfaatan teknologi dalam pembelajaran. Reflective practice bertujuan melatih guru dalam melakukan refleksi pembelajaran untuk continuous improvement. Exploratory practice within Tesol teachers melatih guru dalam melakukan inisiasi refleksi diri dalam membangun pengalaman mengajar yang inovatif.

Berdasarkan penjelesan mengenai pentingnya integrasi TPACK, artikel ini menekankan pada pembahasan integrasi TPACK bagi guru. Artikel ini diharapakan memberikan implikasi bagaimana TPACK dapat dipraktikan oleh guru. Pengabdian ini bertujuan melatih guru bahasa Inggris dalam mengintegrasikan TPACK dalam pembelajaran.

\section{Metodelogi}

Pelatihan ini dilaksanakan di sebuah Hotel di Karawang. Kemudahan akses dan akodomasi menjadi alasan pelaksanaan pelatihan ini dilaksanakan di Hotel. Adapun kegiatan pelatihan melibatkan beberapa guru dari berbagai sekolah di Karawang dari tingkat SMP dan SMK/SMA. Pertimbangan memilih sekolah berdasarkan kepada emotional geography dimana kemudahan komunikasi dan aksesbilitas. Metode yang digunakan dalam pengabdian ini menggunakan narrative inquiry dengan menggunakan wawancara dengan peserta pengabdian.

Peserta pelatihan dibekali dan dilatih mengenai desain TPACK, TELL in Practice dan Relective Practice. Pelatihan diawali dengan penyampaian teori mengenai TPACK. Kemudian strategi desain TPACK dalam lesson plan dan pembelajaran. Fase ini dapat dilihat dari gambar dibawah ini.

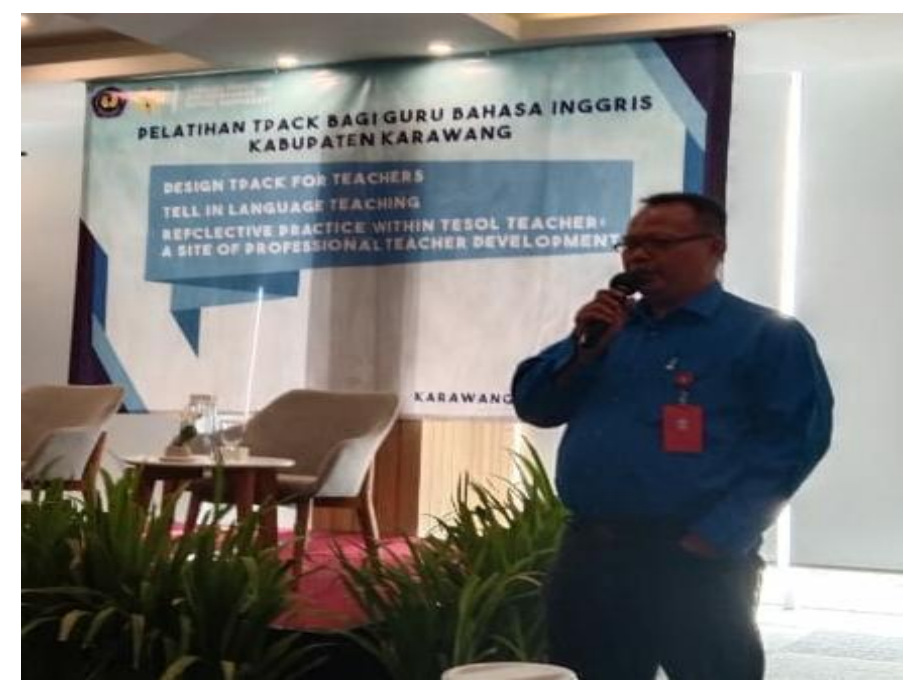

Gambar 1. Penyampaian ringkasan materi pelatihan 


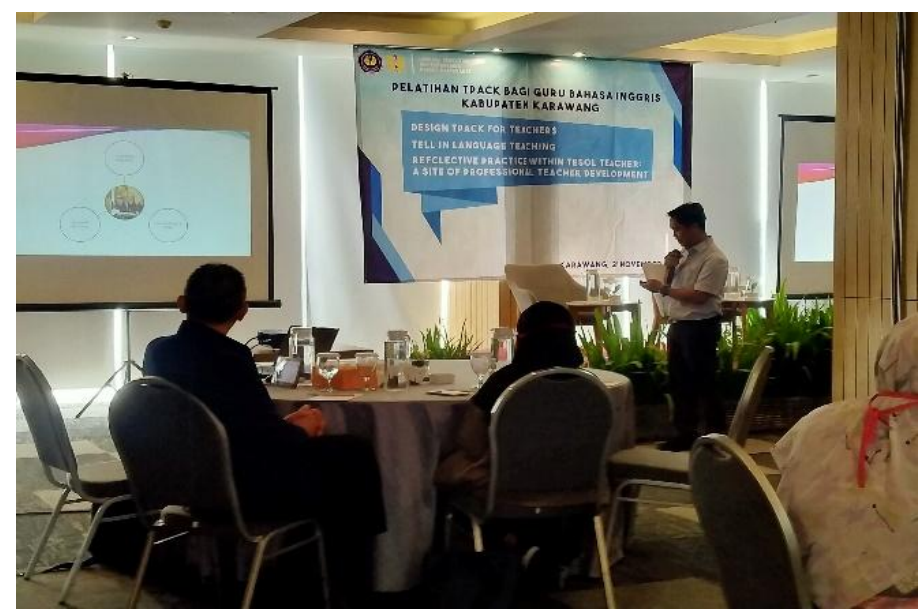

Gambar 2. Interaktif sharing dalam materi pelatihan

Pelatihan dilaksanakan secara interaktif dengan melalui dialog dengan peserta. Peserta aktif mengikuti kegiatan pelatihan dengan bertanya dan mempraktikan TPACK. Peserta distimulasi dengan pertanyaan-pertanyaan seputar pengelaman mereka ketika melakukan pembelaaran daring. Kemudian mereka diminta melakukan refleksi atas pembelajaran yang telah dilakukan.

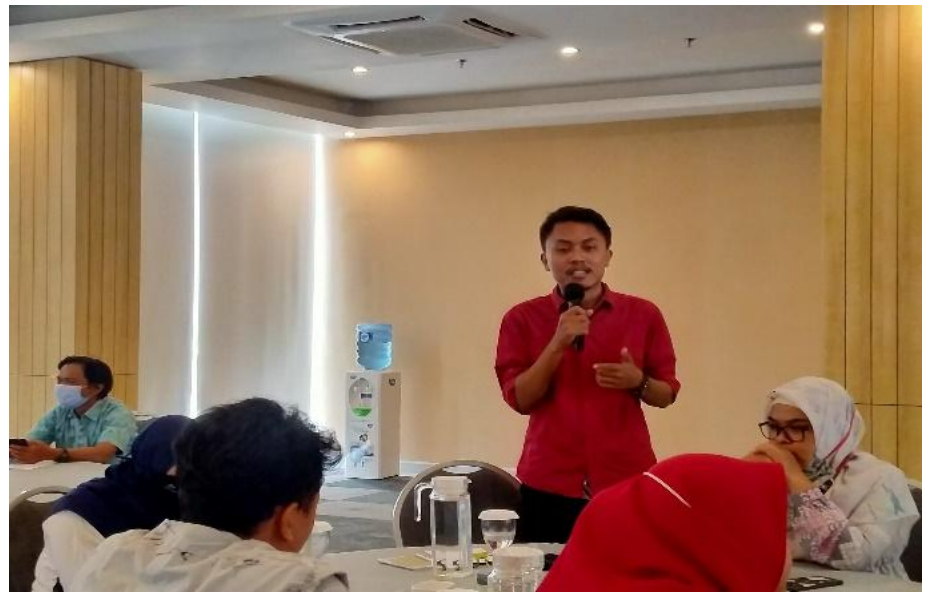

Gambar 3. Keterlibatan peserta dalam pelatihan

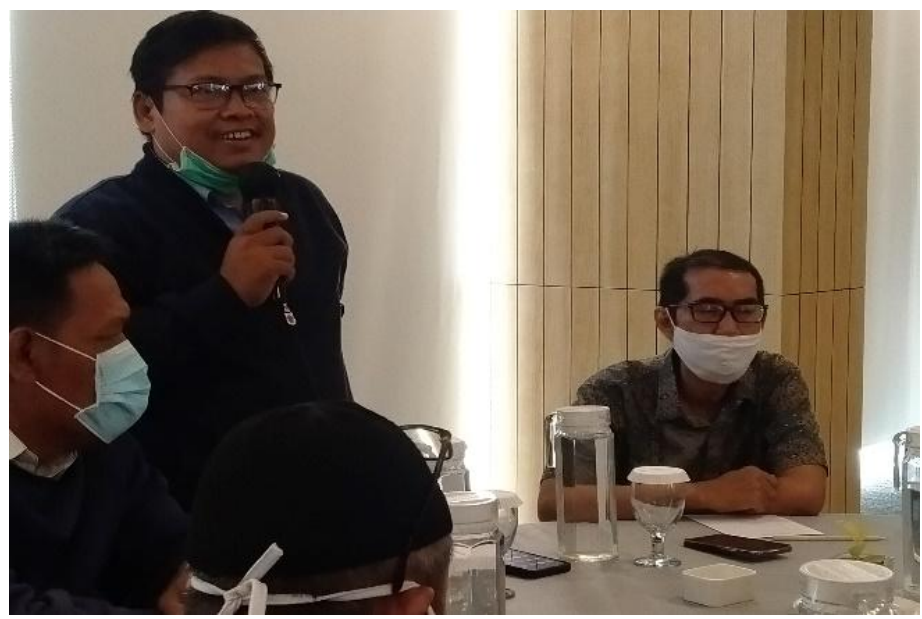

Gambar 4. Interaksi peserta dengan pemateri 
Peserta pelatihan TPACK juga dibekali informasi beberapa platform yang bisa digunakan dalam pembelajaran daring. Topik dari pelatihannya adalah TELL in Practice dimana guru juga diajak mempraktikan platform yang berguna dalam membantu pembelajaran daring. Peserta pelatihan juga tertarik dan terlibat dalam praktik penggunaan platform TELL in Practice. Platform ini gratis diakses dan menarik untuk diimplementasikan dalam pembelajaran daring. Materi disampaikan berorientasikan praktik sehingga peserta dapat terlibat langsung dari alat selulernya masing-masing.

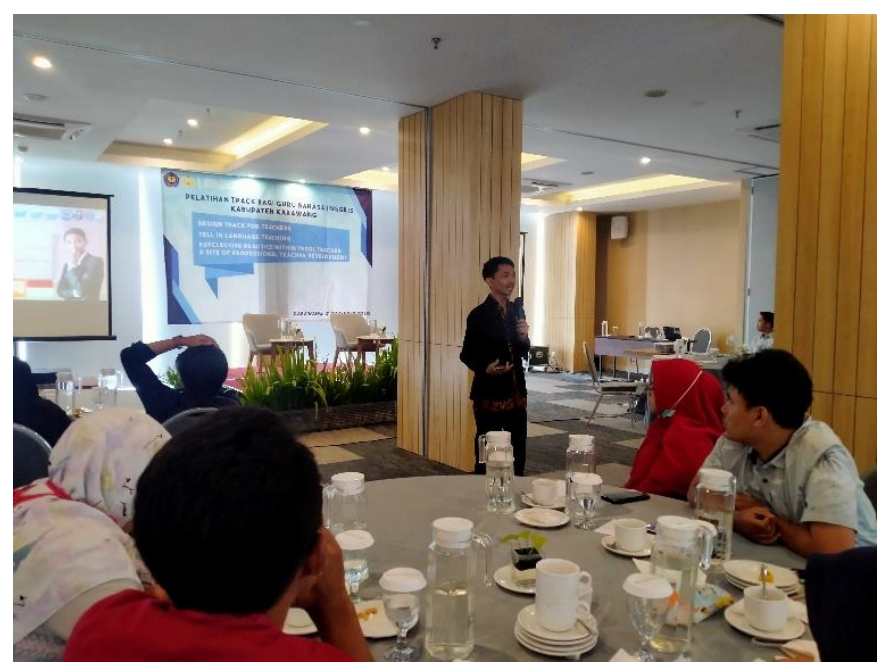

Gambar 5. Penyampaian materi Tell in language learning

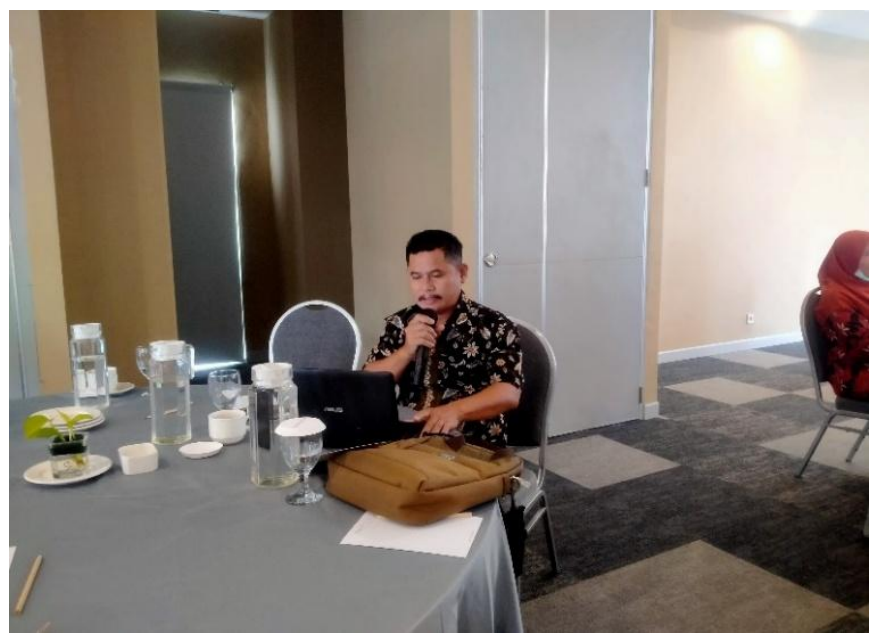

Gambar 6. Interaktif diskusi

Peserta dibekali dan dilatih melakukan refleksi sebagai dasar pengembangan profesi guru. Refleksi ini dimulai mengekslpor apa yang telah diimplementasikan guru dalam mengajar, apa yang keliru dalam mengajar serta mengenai apa yang harus diperbaiki dalam mengajar. Peserta pelatihan juga dikenalkan Puzzle tantangan apa yang menjadi hal menarik dalam melakukan pembelajaran. 


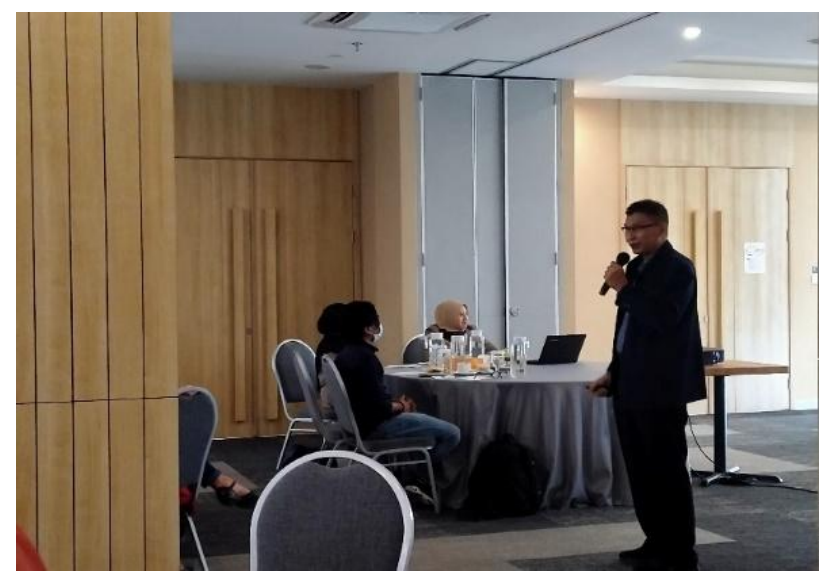

Gambar 7. Penyampaian Materi

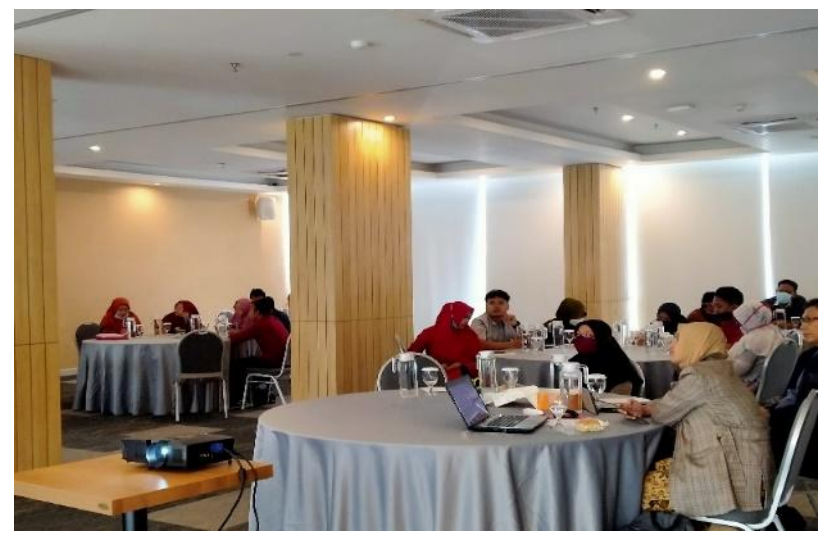

Gambar 8. Interaktif dikusi

\section{Hasil dan Pembahasan}

\section{A. Hasil}

Pelakasanaan pengabdian TPACK mengasilkan beberapa temuan. Adapun temuan ini terdiri peran integarsi TPACK dalam pembelajaran daring, platform teknologi sebagai alat pembelajaran, dan refleksi sebagai sumber pengembangan profesi guru. Adapun informasi temuan lengkap dapat ditelesuri dibawah ini.

1. Proses pelaksanaan pelatihan TPACK terdiri dari penyampaian materi terkait TELL in lanmguage learning, reflectice practice, dan exploratory wiyhin TESOL teachers.

Pelatihan ini disampaikan melalui interaktif workshop. Pemateri dan peserta pelatihan berinteraksi secara aktif dalam menyampaikan materi dan bertanya. Kegiatan workshop ini pula disajikan dalam atmosfir yang tenang dan menyenangkan.

2. Peran integarsi TPACK dalam pembelajaran daring.

Pelatihan memberikan wawasan dan new insight bagi guru-guru dalam melaksanakan pembelajaran daring. Integrasi pedagogi yang luput dari penggunaan teknologi dikenalkan sebagia bagian dari integrasi TPACK. Pedagogi ini membantu guru memiliki ilustrasi yang jelas terkait instruksional desain pembelajaran daring. Sehingga guru dapat membuat RPP online learning dengan mengintegrasikan teknologi, pedagogi, dan materi ajar. Guru juga 
memeroleh wawasan TPACK dalam praktik pembelajaran daring. Hal ini dapat dilihat dari gambar peserta yang mengikuti pelatihan dengan antusis dibawah ini.

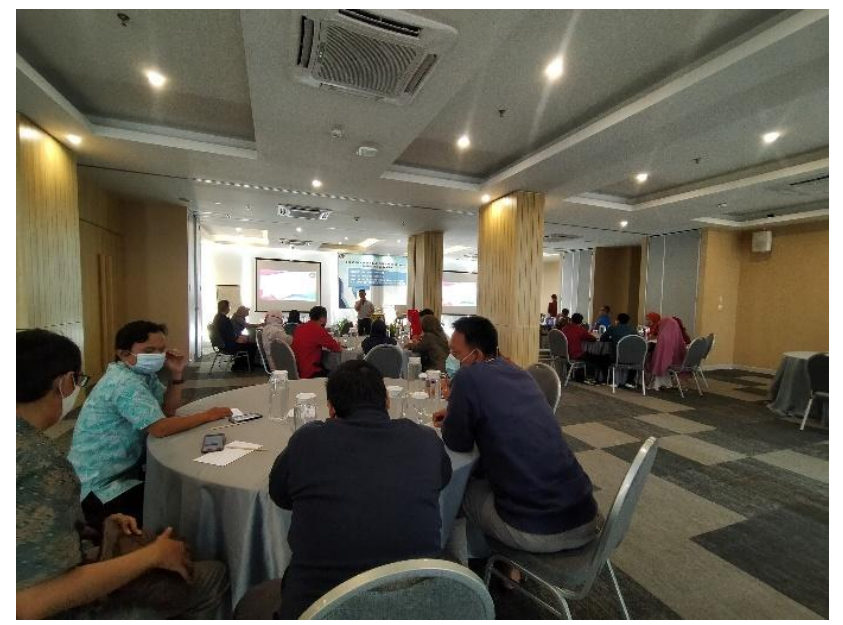

Gambar 9. Interaksi peserta pelatihan

Peserta pelatihan terlibat secara aktif baik dari sisi behavior, kognitif, maupun emosi. Peserta pelatihan dibantu mengkonstruksi TPACK dari pengalaman mengajar dan dibelakali pelatihan integarasi TPACK mulai dari lesson plan hingga pembelarannya.

3. Platform teknologi sebagai alat pembelajaran

Kesetersedian platform gratis yang menunjang pembelajaran membantu guru sebagai alat pembelajaran daring. Alat ini potensial menarik perhatian siswa dalam pembelajaran daring. Keprakstisan dan kebermanfaatan platform juga dapat melibatkan siswa secara sycrhronous.

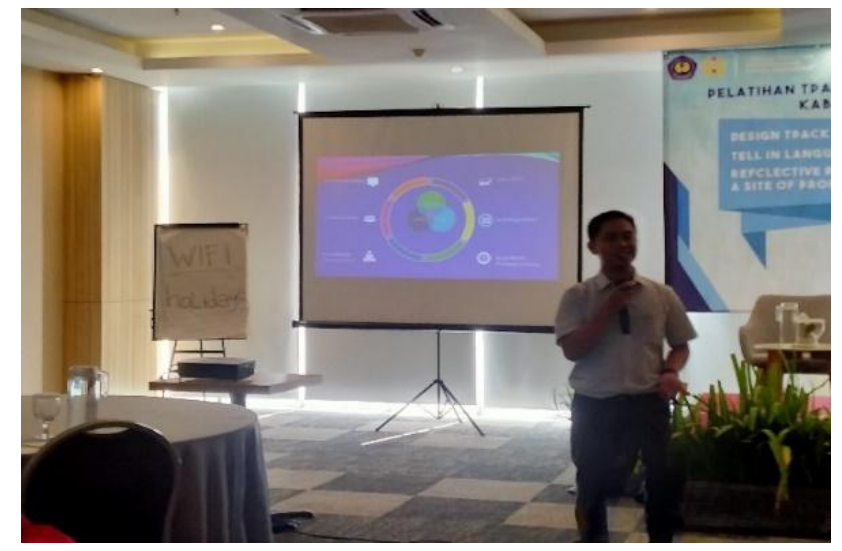

Gambar 10. Penyampaian materi

4. Refleksi sebagai sumber pengembangan profesi guru

Setelah mengikuti pelatihan TPACK dalam pembelajaran guru bahasa Inggris dapat melaksanakan simulasi refleksi untuk peningkatan pembelajaran. Pengembangan profesi guru menjadi hal penting dalam continous improvement bagi guru. Salah satu pengembangan diri guru dapat dilakukan dengan refleksi. Refleksi mempelajari apa yang sudah terjadi, mendalami kekurangan dalam mengajar serta memperbaikinya. Refleksi dimaknai belajar mengajar yang merupakan kompleks, proses linear yang melibatkan eksplorasi berkelanjutan mengenai kepercayaan dan praktik yang bersebrangan dengan pengehetahuan umum termasuk pemahaman secara teori. Guru memiliki puzzle tantangan tersendiri dalam pembelajaran. 
Puzzle tersebut harus diselesaikan dengan baik untuk memperbaiki pembelajaran daring. Kegiatan refleksi praktis dapat ditelusuri dari gambar dibawah ini. Gambar ini merepresentasikan kegiatan pelatihan refleksi guru-guru. Hal ini membantu guru untuk melakukan perbaikan dalam mengajar.

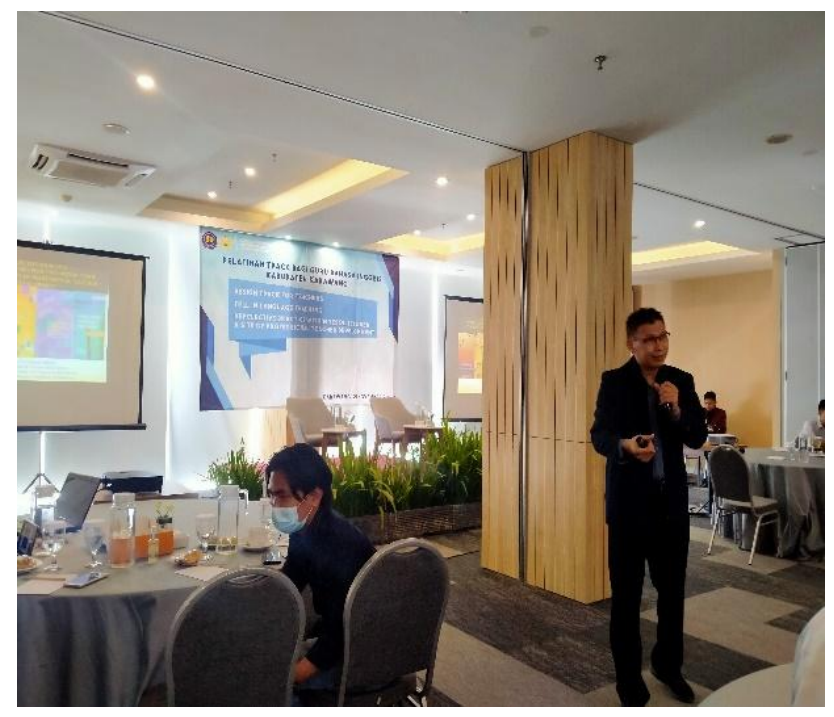

Gambar 11. Penyampaian materi

\section{B. Pembahasan}

1. Peran integrasi TPACK dalam pembelajaran daring

Integrasi TPACK membantu guru dalam mendesain instruksional mengajar. Hal ini dapat diawali dengan perancangan RPP dengan muatan tema/topik yang akan dibahas, pedagogi/strategi mengajar serta alat teknologi apa yang akan digunakan (Drajati, 2020). Perancangan ini membantu guru dalam melibatkan siswa dalam pembelajaran. Keterlibatan ini meliputi behavior, cognitive, dan emosional. Hal ini sesuai dengan Lee, J., Song, H. D., \& Hong, A. J. (2019) menyatakan pentingnya keterlibatan siswa baik dari sisi behavior, cognitive, dan emosional. Integrasi TPACK juga memudahkan pembelajaran yang proforsional sesui dengan teknologi, informasi, dan komunikasi (Kohler et. al, 2013). Hal ini juga diperkuat oleh Jati (2020) menyatakan bahwa web 2.0 membantu siswa terlibat secara aktif dalam pembelajaran daring. Sehingga mempelajari dan mempraktikan TPACK dalam pembelajaran daring menjadi suatu keharusan yang harus dilakukan. Hal ini sejalan dengan Cheng (2017) bahwa TPACK perlu untuk dikenalkan dan dipraktikan khususnya bagi guru-guru senior yang kurang terlalu familiar dengan TPACK. Sehingga peran TPACK dalam pembelajaran daring memiliki posisi yang vital untuk memfasilitasi siswa belajar dengan keterlibatan yang aktif.

\section{Platform teknologi sebagai alat pembelajaran}

Teknologi tidak terlepas dari akses internet untuk memudahkan dalam pembelajaran. Hal ini memberikan kesempatan belajar lebih banyak melalui akses internet (Stödberg, 2011). Platform teknologi juga memberikan banyak implikasi seperti pada the SAMR Model (Puentedura, 2013). Teknologi sebagai alat subtitution dimana teknologi berperan sebagai pengganti langsung. Kemudian teknologi juga dapat berupa augmentation dimana teknologi sebagai pengganti langsung dengan tambahan peningkatan. Modification membantu dalam mendesain tugas ataupun kegiatan lebih menarik. Redefinition dimana teknologi potensial 
dalam menciptakan tugas baru yang sebelumnya belum ada. Salah satu platform teknologi yang dapat digunakan adalah whiteboard.fi. Whiteboard.fi ini alat baik untuk guru maupun siswa untuk penilaian secara formative. Kemudian semantris yaitu platform yang digunakan untuk belajar kosa kata.

\section{Refleksi sebagai sumber pengembangan profesi guru}

Refleksi practice memiliki manfaat dari refleksi yang fokus dan pengujian kritis dari pengalaman mengajarnya yang mana menuju peningkatan dan perkembangan selanjutnya. Hal ini sesuai dengan apa yang dijelaskan oleh Farell (2007) dimana guru mengkaji kepercayaan, asumsi, dan nilai-nilai mengenai pengajaran dan belajar untuk analisi kritis. Refleksi kritis membantu guru dalam mengembangkan profesi guru (Farrell 2018). Refleksi juga memiliki beberapa tujuan. Tujuan itu terdiri dari refleksi diri guru sebagai alat untuk pengehetahuan diri, refleksi untuk pengembangan profesi, refleksi membantu dalam melakukan penelitian dalam mengajar, refleksi untuk meningkatkan pengalaman belajar, dan refleksi sebagai pengajaran dan alat evaluasi (reflective journal).

\section{Simpulan}

Pelatihan TPACK membantu guru dalam mendesain pembelajaran yang mengintegrasikan teknologi, pedagogi, dan konten knowledge. Guru-guru mampu dan dapat menyusun RPP yang melibatkan TPACK didalamnya. Pelatihan ini juga menambah wawasan peserta pelatihan mengenail tool yang potensial untuk melakukan pembelajaran daring. Kemudian peserta pelatihan juga dapat melakukan refleksi sebagai pengembangan profesi guru. Adapun keterbatasan dalam pelatihan ini adalah terbatasnya waktu sehingga belum lengkap dalam menyajikan pelatihan TPACK bagi guru-guru bahasa Inggris. Pengembangan pelatihan selanjutnya dapat ditingkatkan dengan memfokuskan pada desain instruksional pengajaran bahasa berbasis TPACK.

\section{Ucapan Terima Kasih}

Ucapan terima kasih yang setinggi-tingginya kepada LPPM Unsika yang telah mendanai kegiatan Pengabdian kepada Masyarakat ini. Apresiasi setinggi-tingginya juga kami sampaikan kepada seluruh pemateri undangan dan peserta pelatihan yang bersedia ikut serta dengan antusias.

\section{Daftar Pustaka}

Chai \& Koh. 2017. Changing teachers' TPACK and design beliefs through scaffolded lesson design model (STLDM). Journal of Learning: Research \& Practice. Routledge.

Cheng. 2017. A survey of native language teachers' technological pedagogical and content knowledge (TPACK) in Taiwan. Journal of Computer Assisted Language Learning. Vol. 30,2017-Issue 7.https://www.tandfonline.com/doi/abs/10.1080/09588221.2017.1349805.

Chai, C. S., Tan, L., Deng, F., \& Koh, J. H. L. (2017). Examining pre-service teachers' design capacities for web-based 21st century new culture of learning. Australasian Journal of Educational Technology, 33(1), 1-20. https://doi.org/10.14742/ajet.3013.

Drajati, Arifah, N. 2020. Pembelajaran bahasa Inggris dengan framework TPACK: kesempatan \& tantangan.. Surakarta: Yuma Pressindo. 
Farrell, T. S. C. (2007). Reflective language teaching: From research to practice. New York: Continuum.

Jati, Gumawang. 2020. Inovasi teknologi dalam pembelajaran bahasa Inggris from stand-alone computer to mobile phone. Surakarta: Yuma Presindo.

Kementrian Pendidikan \& Kebudayaan. 2020. Surat edaran tentang pelaksanaan kebijakan pendidikan dalam masa darurat penyebaran Covid-19.

Koehler, Mishra, \& Chain. 2013. What is technological pedagogical content knowledge (TPACK)? Cite Journal, Vol. 2. https://citejournal.org/volume-9/issue-109/general/what-is-technological-pedagogicalcontent-knowledge/.

Murphy, K. L., DePasquale, R., \& McNamara, E. (2003, November). Meaningful connections: Using technology in primary classrooms. Beyond the Journal: Young Children on the Web. Retrieved on April 28, 2013 from http://www.naeyc.org/files/yc/file/200311/TechInPrimaryClassrooms.pdf

Pinkley, D. (2010). Computer technology in the primary classroom. Retrieved on April 23, 2013

fromhttp://www.pearsonlongman.com.uy/sitio/downloads/EFF/1091_CompTech_Engli sh_FNL.pdf

Rakerda, Hilda (2020). Active learning pada pembelajaran bahasa Inggris dengan kerangka TPACK. Surakarta: Yuma Presssindo.

Stödberg, U. 2011, "A research review of e-assessment", Assessment \& Evaluation in Higher Education, Vol. 37, No. 5, pp. 591-604. 